\title{
HAEMODIALYSED PATIENT WITH FRACTURE MANAGEMENT
}

\author{
Paritosh Chandra Debnath ${ }^{1}$
}

\section{Introduction:}

Surgical management in a case of end stage renal failure who needs regular haemodialysis requires special attention. As patient has to attend dialysis centre in every two alternative days surgical management of fracture has to perform within two days or before the next visit to dialysis Centre. This is a rare case and surgery was done very carefully to avoid unusual bleeding, fluid overload and heart failure.

After preoperative assessment open reduction and internal fixation of malleolar fracture was started by spinal anesthesia with a competent Anesthesiologist after 12 hour of haemodialysis and discharge before visit to dialysis centre. Pre operative and Post operative period was uneventful and union was satisfactory within 2 months.

\section{Case report:}

A patient of renal failure aged about 40 years came to me at Mirpur Adhunik Hospital on March 2007 with displaced fracture of Medial malleolus of 7 days old. According to him he is a patient of end stage renal failure who needs regular haemodialysis in every two alternate day. He was refused to be operated in fear \& failure of uninon . I evaluate the patient by checking the relevant investigations and found that he had additional problem of hypertension with mild enlarge heart, osteoporosis and oedema of the face and ankle.

1 then consult with Nephrologist, Urologist, Cardiologist and Anesthesiologist before suggesting him for open reduction and rigid internal fixation with plate and Malleolar screws. Operation was done 12 hours after haemodialysis with minimum Ultracaine in Spinal Anaesthesis to avoid unusual bleeding and fluid overload. Preoperative and postoperative period were uneventful. Patient was discharged after 1st POD to attend haemodialysis centre after checking the wound.

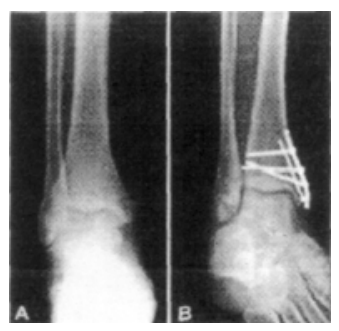

Fig:1

\section{Discussion:}

Fracture is common in vertebra, ribs, and neck of the femur in Haemodialysed patient but malleolar fracture is not usually seen. Minor trauma may cause fracture in

osteoporotic bone. Osteoporosis is common in renal failure patient. Proper assessment and timing of operation is important. Heart failure and unusual bleeding is common in haemodialysed patient. To avoid unusual bleeding, operation was performed after 12 hours of haemodialysis and no active bleeding was seen. Antihypertcnsivc drugs for high BP. Antibiotic and IV fluid were used very carefully to avoid complication. The older the patient the higher the complication rate at bone and joint resulting from long term haemodialysis. Stiches were removed after 10 days and plaster was removed after 4 weeks. Ankle exercise and oral vita-D with calcium were advised. Weight bearing was started after 2 months. Union was satisfactory after 2 months. He visited monthly for 2 months and 2 monthly for next 4 months.

\section{Conclusion}

Fracture in a patient of renal failure with haemodialysis is rare. A few precautions have been taken before doing surgery. Surgery should be done after one day or 12 hours after haemodialysis to avoid unusual hemorrhage. After or before surgery Claxene instead of Heparin should be used at the time of haemodialysis. Any suitable analgesic can be used to minimize pain after surgery in this case as no further effect of analgesic on non functioning kidney but analgesic (NSAID) should be restricted in chronic renal failure. Proper assessment of the patient, timing of operation, rigid fixation, early exercise and vitamin D with calcium might contribute the satisfactory result.

\section{Refference:}

1. Ricker II. Christansen M. Rodba P. Bone mineral content in patient on prolonged maintenance hemodialysis a three year follow up study.chn Nephrol 1983:20:302-307.

2. Morita A, fabata T. Inoue T. Nishizawa Y. \1ori H. The effect of oral Ict-hydroxycalciferol treatment on bone mineral density in hemodialysis patients. Chn Nephrol 1996; 46 : 389393.

3. Chest nut. CH. Bonemass and exercise . Am J Med 1993: 95(Suppl 5A) 34S-36S,

4. Schuab P C. Murphy G Tzamaloukas AH ct all . Femoral neck fracture in patient receiving long term dialysis co tn Orthpl'WO: 260:224-231.

Dr. Paritosh Chandra Debnath, Associate Professor of

Orthopaedics. Shaheed Suhrawardy Medical College. 